\title{
Promoting the understanding of electronic components and circuit parameters by using didactic dynamic pictures - qualitative analysis of research results
}

\author{
Krzysztof Krupa \\ University of Rzeszow, 35-959 \\ Rzeszow, al. Rejtana 16C, Poland \\ Email:kkrupa@ur.edu.pl
}

\begin{abstract}
This article describes the qualitative analysis of the research results of the effectiveness of promoting an understanding of the parameters of electronic components and circuits by using dynamic circuit and block diagrams as well as the dynamic characteristics integrated with them. The introduction highlights the characteristic way of understanding the parameters of electronic components and systems and an outline of my research conducted in this area. The second chapter presents a typology of the dynamic pictures used and a description of sample animations. The third chapter contains the explication of the concepts of understanding electronic components and circuits. The fourth chapter presents the description of the research, while in chapter five the qualitative analysis of the research results is shown, from which the conclusions are contained in chapter six.
\end{abstract}

\section{INTRODUCTION}

$\mathrm{I}$ $\mathrm{N}$ MOST mechanical structures, moving parts play a major role. They are integral to sensory cognition. The phenomena taking place inside electronic structures are not available to sensory cognition, which is why images play a leading role in the teaching of electronics. Since these phenomena exhibit variations in time, the didactic dynamic picture, visualizing the time dependence, may affect the effectiveness of teaching electronics. Part of my research on the effectiveness of using dynamic pictures was spent teaching the meanings of the parameters of electronic components and circuits. They represent a part of the test results on the effectiveness of teaching using didactic dynamic pictures that were included in the dissertation [2].

\section{Didactic Dynamic Pictures In Shaping The UNDERSTANDING OF ELECTRONIC COMPONENTS AND CIRCUIT PARAMETERS}

Didactic dynamic pictures used in the teaching-learning of electronics were divided into four groups. They perform the following didactic functions: illustrating the operation of electronic components, functioning of electronic compo- nents in basic work systems and illustrate the construction and operation of electronic circuits. In order to visualize the electronic components, dynamic area models are utilized. The operations of electronic components in basic systems, can be presented by the analogy of hydro-mechanical and dynamic schematics. The functioning of electronic circuits can be presented by using dynamic circuit diagrams and composite structures using dynamic flowcharts. Dynamic characteristics may be used for a detailed visualization of the parameters [4].

In order to shape the understanding of electronic components and systems parameters, the most appropriate images are those under which direct visualization of parameters occurs. These include dynamic circuit diagrams and dynamic flowcharts and corresponding dynamic characteristics.

Figure 1 shows an application, visualizing the operation of a basic amplifying circuit, constructed using a bipolar transistor. The application consists of two modules. On the left is a dynamic scheme, on the right the dynamic characteristic, which was operably linked to the diagram. The value of the input voltage to the system can be changed by using a slider. According to the characteristics of the bipolar transistor, the input voltage's $U_{\mathrm{BE}}$ changes are reflected in the value of the current flowing through the base of the transistor - $\mathrm{I}_{\mathrm{B}}$. According to the characteristics of transition, changes in the intensity of the base current of the transistor causes proportional changes in the current of the collector - $\mathrm{I}_{\mathrm{C}}$. Changes in the collector's current, which is also the current of the resistor $\mathrm{R}$, causes changes in voltage across the resistor, working together with the transistor in the voltage divider, whereby it also changes the output voltage of the system.

The scheme uses a series of dynamic elements. For example, numeric values of parameters such as base-emitter voltage $\left(\mathrm{U}_{\mathrm{BE}}\right)$, the base current $\left(\mathrm{I}_{\mathrm{B}}\right)$, the collector current $\left(\mathrm{I}_{\mathrm{C}}\right)$ and the voltage at the collector's resistor $\left(U_{R}\right)$ and the output voltage $\left(\mathrm{U}_{\mathrm{CE}}\right)$. The magnitudes of these parameters are further displayed, in graphic form, with the help of dynamic 
arrows whose size varies depending on the value visualized by the arrow's signal.
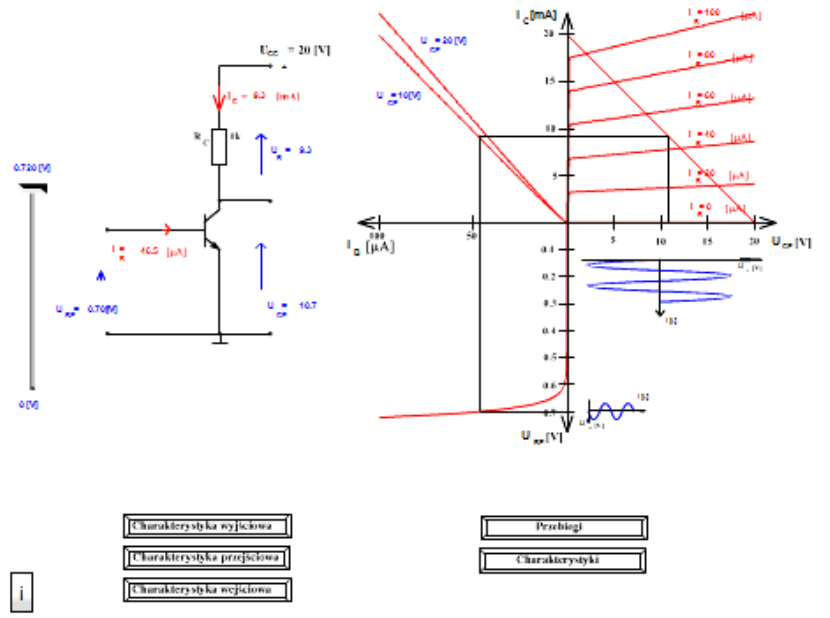

Figure 1. Didactic dynamic scheme with dynamic characteristics. The application shows the OE transistor amplifier [4].

Placed next to the schema, is a collection of dynamic characteristics of the static characteristics of the bipolar transistor in a common emitter's circuit. Includes the input characteristics $I_{B}=f\left(U_{B E}\right)$, transient characteristics $I_{C}=f$ $\left(\mathrm{I}_{\mathrm{B}}\right)$ and the output characteristics $\mathrm{I}_{\mathrm{C}}=\mathrm{f}\left(\mathrm{U}_{\mathrm{CE}}\right)$. The output's characteristics also draws the static characteristics of the resistor $\mathrm{R}$. The main element in the dynamic characteristics are the lines indicating the individual parameters of the static characteristics. Furthermore, applied were dynamics, plotted out on the screen of timeline charts, of sinusoidal signals present at the input and the output of the system. All elements of the dynamic characteristics can be freely switched on and off using the appropriate buttons.

Figure 2 shows a different kind of teaching dynamic picture - a dynamic block diagram of an AC adapter for continuous operation. Despite the fact that all the blocks and timing diagrams of the system were presented, the application allows for their stepwise actuation by pointing the cursor over their names and blocks.

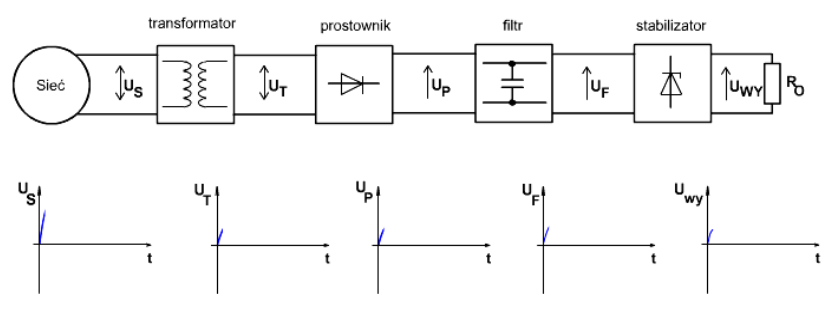

Figure 2 is a block diagram showing the dynamic power supply for continuous operation [4].

The application makes it feasible to present the essence of the shaping signals in particular functional blocks of the system. It is the basis from which to present, to the students, the construction and operation of consecutive blocks, such as the transformer, rectifying circuit, filter and stabilizing system.

The article shows only two examples of the teaching dynamic pictures. For empirical research purposes, much more of these aids were developed. These encompassed ten issues of analog electronics. The effectiveness of the application presented in the article has been confirmed [3]. Also undertaken were a series of works, aimed at creating a didactic dynamic picture visualization of digital systems. They have been applied in teaching materials used for teaching electronics over the Internet. These are applications that act as simulators of basic digital electronic systems.

\section{UNDERSTANDING THE PARAMETERS OF ELECTRONIC COMPONENTS AND CIRCUITS}

This article assumes that understanding is the discovery of such content in objects, as their significance, meaning, structure, function, role, origin, durability, usefulness, look, what it does, how it arises, what it interacts with, the category to which it belongs and what specific characteristics does it possess [1]. One of the areas of understanding electronic engineering is to understand the parameters of electronic components and systems [3], which the student exhibits by their behavior relative to the described, in any way (image, symbol, text), element or electronic system [3]: assigns characteristic parameters to the element, describes the main characteristics of electronic components and systems, determines the unit of a given parameter, estimates the value of the given parameter, assigns characteristics to the stated element or electronic circuit, outlines the characteristic parameters of electronic components and systems, identifies, explains, indicates the essential points of the characteristics of electronic components and devices, explains the essence of the parameters of electronic components and devices, solves problems (including computing) using the parameters of electronic components and systems and selects a parameter or characteristic element or system to solve the design problem.

The set of these manifestations of understanding was used to construct the test tasks for the purpose of measuring the effectiveness of dynamic pictures in the development of understanding the parameters of electronic components and systems [3].

\section{DESCRIPTION OF THE COURSE OF RESEARCH}

Research of the efficiency of shaping the understanding of the parameters of electronic components and systems was carried out as part of a study involving the effectiveness of teaching electronics using didactic dynamic pictures on the example of the education process of students of technical and information technology. A didactic experiment, as the research method, was adapted and ran based on the parallel group technique. The study included students of technical- 
informatics education, educated under the three-year undergraduate studies and the five-year study mode.

The research used 120 didactic dynamic pictures presented to students of the experimental group consisting of ten lectures on analog electronics. The control group was given only static pictures were. After each lecture, students in both groups were subjected to a 20 task test. Four weeks after the last lecture, a test was given containing sixty tasks from ten sections of analog electronics.

Quantitative analysis allowed for the confirmation of the hypothesis, in which it was assumed that the use of didactic dynamic pictures contributes to the efficiency of promoting the understanding of parameters of electronic components and systems. In order to fully present the results of the test, qualitative analysis was used [3].

\section{V.QUALITY ANALYSIS OF TEST RESULTS}

Qualitative analysis allows for the identification of the kinds of difficulties faced by students in the experimental and the control groups while solving the tasks of understanding the parameters of electronic components and systems.

The first task was to indicate whether the impedance is at its lowest when the frequency of the current flowing through the serial RLC circuit is equal to the resonant frequency.

1. When the frequency of the current flowing through the system of equations is analyzed, resonant frequency of the circuit impedance is the lowest. true / false - underline the right answer.

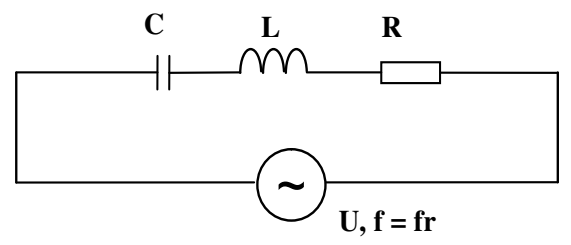

RLC circuits in serial configurations, parallel and mixed are widely used in electronics, especially in the input circuit of the radio. In the case of this task, the experimental group received $83 \%$ correct responses relative to the control group that received a score of $41 \%$.
2. Please calculate the equivalent resistance of the circuit. Select the correct answer with a cross in the table.

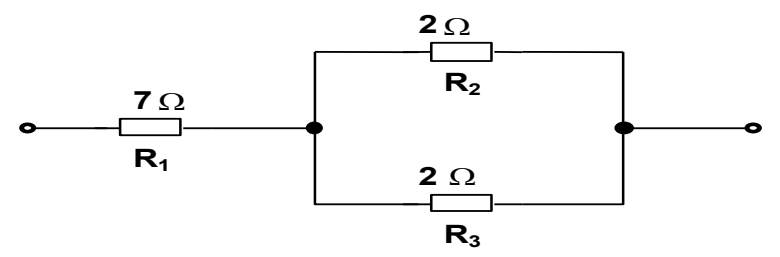

\begin{tabular}{|l|l|l|}
\hline 1 & $8 \Omega$ & \\
\hline 2 & $5 \Omega$ & \\
\hline 3 & $4 \Omega$ & \\
\hline 4 & $16 \Omega$ & \\
\hline
\end{tabular}

The solution to the 2nd task was to calculate the supplementary resistance of a circuit consisting of resistors connected in series and in parallel.

The experimental group received a score of $78 \%$ correct responses, and control group 48\%. In the experimental group, $24 \%$ of students made the wrong choice as a result of not doing any calculations on the test sheet. In the control group, however, this situation occurred in $41 \%$.

In view of the fact that didactic dynamic pictures do not support directly the skills of solving mathematical equations, it may indicate that there is another, deeper reason for the significant difference in the results of the groups at the expense of the control group. The didactic work with students, in the experimental group, noted that they often rely on lectures where dynamic hydraulic analogies are used. Facilitating the understanding of the presented phenomena, thus making it possible to avoid erroneous algorithms during problem solving, which were observed among those students who never dealt with analogies.

In a further, third task, a time constant of an $\mathrm{RC}$ circuit with specified parameters had to be calculated.

3. Calculate the time constant of the $\mathrm{RC}$ circuit with parameters: $\mathrm{R}=100 \mathrm{k} \Omega, \mathrm{C}=10 \Omega \mathrm{F}$.

The solution to this task depended on the reproduction of the correct mathematical expression, substitution of the given values into the formula, appropriate transformation of data prefixes and the performing of calculations. The experimental group received a score of $17 \%$ correct answers, while the control group $34 \%$. The grading of the solution to the problem was based on the proper conversion of units.

In the experimental group, $73 \%$ of students did not attempted to solve this task, whereas in the control group, $62 \%$ reported omissions. This shows a complete inability to solve the task. A similar conclusion can be drawn on the basis of an incorrect formula, which was reported in $7 \%$ of the responses of the experimental group and in $3 \%$ of the responses of the control group of students.

The ability to apply the message in typical situations with regard to the understanding of the electronic parameters was 
measured with the use of task 4, in which the current-voltage characteristics of a semi-conductive diode should be drawn. On this characteristic, the forward voltage should also have been marked.

4. Please draw a semi-conductive diode's characteristics and highlight the forward voltage.

This task was solved correctly by $54 \%$ of the students in the experimental group and $34 \%$ of the control group. In the experimental group, a reported $12 \%$ had partial responses containing omissions in the description of the axis on the graph, and $17 \%$ had incorrect charts. In the control group, $31 \%$ of such completely incorrect responses were reported. In $21 \%$ of the tasks, of the control group, students did not attempt to find a solution. In the control group, in $31 \%$ of cases, the answer was completely random, for example, a student drew a sinusoidal waveform. In the experimental group, this phenomenon occurred in $17 \%$ of the cases. These experimental lectures exposed the dynamic characteristics of diodes, which illustrated the relevant parameters of their application in electronic circuits.

Obtaining a solution to task no. 5, it was crucial to indicate which of the expressions describes the amplification of current of a bipolar transistor.

\begin{tabular}{|c|c|c|c|c|c|}
\hline \multicolumn{6}{|c|}{$\begin{array}{l}\text { 5. Which of the expressions describes bipolar transistor } \\
\text { current amplification of the OE circuit?................. - } \\
\text { check the right answer }\end{array}$} \\
\hline$A: \quad \frac{I_{C}}{I_{B}}$ & $\frac{U_{B E}}{I_{B}}$ & $C:$ & $\frac{U_{B E}}{U_{C E}} ;$ & $D:$ & $\frac{I_{E}}{I_{B}}$ \\
\hline
\end{tabular}

The experimental group, for this task, received a score of $22 \%$ correct answers, while $48 \%$ was attained by the control group. Bipolar transistor current gain was mistakenly identified, by specifying the ratio of the emitter current to base current, $7 \%$ of the students in the experimental group and $31 \%$ of the control group. This demonstrates a better understanding of this parameter by persons participating in lectures, in which no didactic dynamic pictures were used. $46 \%$ of the responses in the experimental group and $17 \%$ in the control group indicated that the current gain is calculated by using the expression containing the voltage ratio value UBE to UCE. In this case, a separate dynamic picture was not applied, from which, in a direct manner, the issue of the current gain can be assimilated.

In task no. 6 it was necessary to describe the "minimum holding current". In the control group there was no single correct answer, while in the experimental group, the number of correct responses was $37 \%$ of the total number of results. This data suggest a beneficial impact of the experimental agent on the effectiveness of understanding the parameters.
6. Please describe the concept of "minimum holding current".

Majority of the students $(69 \%)$ in the control group did not specify the electrodes of the thyristor, in which the parameter, included in the job, is expected to be. One student from the control group mistook the holding current with the conduction current $(4 \%)$. The experimental group reported a $15 \%$ omissions of tasks, while $14 \%$ of the respondents in the control group did not attempt to solve the task.

Further, task no. 7 referred to the skills used in typical situations in terms of understanding the parameters of semiconductive switching elements. Solving this task required plotting out the current-voltage characteristics of the triac. $66 \%$ of the students in the experimental group and $38 \%$ of students in the control group solved the task correctly.

\section{Please draw the characteristics of the triac. Pay attention to the description of the axis.}

Basic mistakes committed during problem solving consisted of drawing unidirectional triode thyristor $(9 \%$ in both groups) or bidirectional diode thyristor. Such errors were committed by $15 \%$ of the students in the experimental group and $24 \%$ in the control group. In the experimental and control group, there were no omissions of the task. A significant difference in both groups' output results can testify to the high efficacy of the use of didactic dynamic pictures in shaping the understanding of parameters.

Similarly, high results were obtained in the task 8 , in which the person being tested needed to indicate a relationship between the parameters of $\mathrm{I}_{\mathrm{G} 1}$ and $\mathrm{I}_{\mathrm{G} 2}$ on the current-voltage characteristics of the thyristor $\left(\mathrm{IA}=\mathrm{f}\left(\mathrm{U}_{\mathrm{AK}}\right)\right)$.

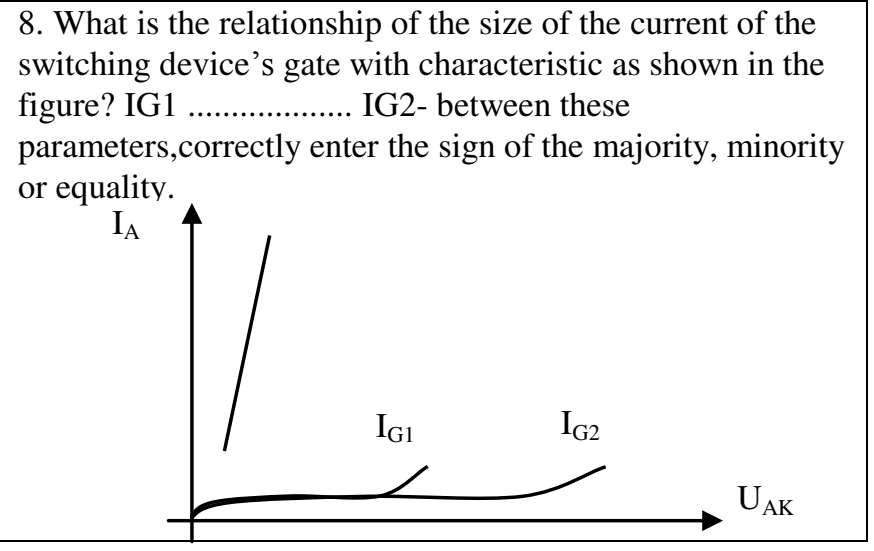

In this case, the experimental group received a score of $88 \%$ correct responses, while the control group 59\%. The ability of answering this task indicates skills in identification, assessment and understanding of the parameters affecting the operation of the switching elements.

The task of no. 9 was to draw a phototransistor's output characteristics. 
9. Please draw a phototransistor's output characteristics. Pay attention to the description of the axes and constant parameters.

The ability to draw the characteristics showed $27 \%$ of the students in the experimental group and $14 \%$ of students in the control group. The experimental group reported $58 \%$ omissions of the job or a completely wrong realization of it, while in the control group these solutions were $72 \%$. In the experimental group, $24 \%$ of the tasks were incompletely resolved. Characteristics properly drawn, from a graphical point of view, were not described with proper parameters nor have the axis' signatures drawn into $(\mathrm{IC}=\mathrm{f}$ (UCE), $\mathrm{E}=$ const).

The level of understanding a photoresistor's parameters was measured with the help of task $10.39 \%$ of the students in the experimental group correctly answered the question, while the control group attained $62 \%$ correct answers. In this case, there was no positive impact of the didactic dynamic pictures on the level of to understanding the parameters.

\section{Please describe the parameter of "dark resistance"}

$22 \%$ of students in the experimental group turned the process around by switching the cause of the phenomenon with its effect, for example, one of the responses reads: "it is a small light caused by high resistance". In the didactic dynamic picture, it was shown how a photoresistor works under conditions of complete darkness, however, the name of its resistance was not specified.

Task no.11 was dedicated to the understanding of the parameters, in which the essence of the squareness ratio needed to be explain. Here the experimental group received a result of $5 \%$, while the control group got $10 \%$ correct answers.

11. Please explain the nature of the parameter: squareness ratio. In the explanation please use an appropriate figure and expression.

None of the dynamic pictures used in the study directly referred to this parameter, however, the issue of the steepness of the frequency characteristics of filtration systems and a tuned generator was presented with the help of the didactic dynamic pictures. However, this proved insufficient.

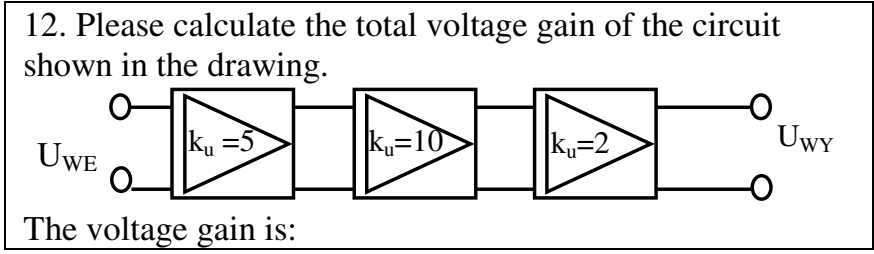

The next task (12), relating to the understanding of the electronic circuit parameters, concerned the calculation of the voltage gain of a triple set of amplifying blocks, connected in series, with a given intensification.

In this task the experimental group received $49 \%$, while the control group received $83 \%$ of correct answers. As is apparent from the number of correct answers, this task was relatively simple, however, in this case, no positive effect of the experimental agent was noted. Among the errors in solving this task, the most frequent were attempts the summation of individual gain values. This phenomenon occurred in $36 \%$ of the answers given by the students in the experimental group and $6 \%$ of students in the control group. The other students did not attempt to solve the task.

The next task (13) related to the ability of using the messages in problematic situations referring to the understanding of the electronic circuit parameters. In this task, the input voltage of the amplifying circuit, with feedback, had to be calculated, using the data contained in the problem.

13. Please calculate what the input voltage is given to the system if there is voltage at the output of $10 \mathrm{~V}$. The $\beta$ value is -0.1 and the gain of the amplifier $\mathrm{k}=100$.

$\mathrm{U}_{\mathrm{WE}}$

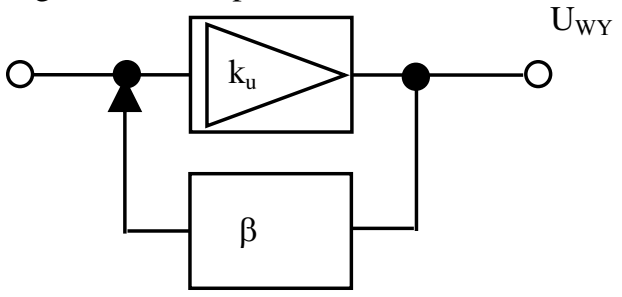

The experimental group received a score of $12 \%$, while the control group achieved $3 \%$ of correct answers. The experimental as well as the control group reported the same number $(24 \%)$, which acknowledges that the basic pattern of amplification of a circuit, with feedback, is well known to students and the result of this study is caused by the control group's student's inability to exploit it.

In task 14 the characteristic of a secured progressive AC adapter had to be draw. The experimental group reported $32 \%$, while only $3 \%$ of correct answers in the control group.

\section{Please draw the load carrying characteristics of a power supply with progressive protection.}

In the experimental group's answers, the correct shape of characteristics were included, but did not adequately describe its axis. There were $9 \%$ of such responses. In the control group, $6 \%$ of the responses contained the mistake of shifting the graph's $y$-axis for the x-axis. This demonstrates the misconception of the nature of dependency on the phenomena presented with the help of the overload characteristics. It should be noted that the didactic dynamic picture was not used directly in illustrating the activities of 
progressive security. A higher percentage of accurate answers, in the experimental group, demonstrates the indirect effects of the didactic dynamic pictures.

The next task (15) related to the measurement of the ability to use the message in typical situations, within the meaning of the parameters of electronic systems.

\begin{tabular}{l}
\hline 15 Graph showing the following equation such as \\
$\mathrm{f}=\mathrm{f}\left(\mathrm{U}_{\mathrm{CC}}\right)$ illustrates:
\end{tabular}
\begin{tabular}{|l|l|l|}
\hline 1 & $\begin{array}{l}\text { frequency response of the output signal when } \\
\text { changing the amplitude }\end{array}$ & \\
\hline 2 & $\begin{array}{l}\text { frequency of the amplitude of the output signal } \\
\text { when changing the supply voltage }\end{array}$ & \\
\hline 3 & $\begin{array}{l}\text { frequency response of the output signal when } \\
\text { changing the supply voltage }\end{array}$ & \\
\hline
\end{tabular}

It was necessary to explain the essence of the characteristics described for each model. The results obtained in this work are the following: the experimental group - 78\% correct answers; control group - 90\%. Distractor 2 was chosen by $12 \%$ of students in the experimental group and $10 \%$ of the students in the control group. Three people in the experimental group showed distractor 3 [3].

\section{CONCLUSION}

Experimental studies have shown that the use of the didactic dynamic pictures has an important influence on the understanding of the parameters of electronic components and systems. Qualitative analysis of the results allow the following conclusions:

- students of the control group more often than the students of the experimental group did not attempt to solve the task,

- control group students more frequently than in the experimental group gave accidental or absurd answers,

- mistakes made by the students in the control group are more important than the mistakes made by the students in the experimental group.

Qualitative and quantitative analysis of the results of the studies on the effectiveness of using didactic dynamic images in the development of understanding the parameters of electronic components and systems confirm the hypothesis, in which the expected positive effect of the experimental factor.

\section{REFERENCES}

[1] E. Franus (2000), Wielkie funkcje technicznego intelektu. Kraków.

[2] K. Krupa (2013), Efektywność nauczania elektroniki z zastosowaniem dydaktycznych obrazów dynamicznych na przykładzie studentów kierunku edukacja techniczno-informatyczna, doctoral dissertation manuscript, APS, Warszawa.

[3] A. Marszałek (2001), Elektronika w edukacji technicznej dzieci i młodzieży. Rzeszów.

[4] K. Krupa (2011), Tworzenie dydaktycznych obrazów dynamicznych przykłady realizacji struktur mechatronicznych in Wokół mechatroniki. red. W. Furmanek, L. Leniowska, Rzeszów. 